\title{
A PROBLEM OF RIGHTS ARBITRATION FROM THE TALMUD
}

\author{
Barry O’NEILL \\ Department of Industrial Engineering and Management Sciences, Northwestern University, \\ Evanston, II. 60201, U.S.A.
}

Communicated by E. Kalai

Received 24 November 1980

Revised 13 July 1981

\begin{abstract}
A man dies leaving certain amounts of his estate to each of his sons, but the amounts sum to more than the total available. Various solutions are discussed, some based in the theory of games. The method endorsed here regards the problem as one of rights arbitration in which the division is based on interpreting the applicable rules, rather than on weighing the parties' powers and possible benefits.
\end{abstract}

Key words: Rights arbitration; bargaining; recursive completion.

\section{Introduction}

In the vocabulary of professional arbitration (Elkouri, 1952; Spielmans, 1939), rights arbitration refers to situations covered by pre-existing rules or customs. When a dispute has arisen because the rules are unclear, the arbitrator makes a judgement about the meaning of the rules, and in this way decides the parties' rights.

The alternative type of arbitration is interests arbitration, in which there are no pre-existing rules, and in which judgements are made on the parties' interests $s_{\text {i.e., }}$ the relative benefits each would receive.

In the case of rights arbitration the arbitrator must clarify the meaning of the rules or in some cases resolve a contradiction among prevailing rules. If an employee is discharged for violating a rule against loafing and the case is brough: to arbitration, the arbitrator must make a decision as to whether the employee's actions constituted loafing. The decision will be a semantic one, guided by precedent.

If union and management take a wage proposal to arbitration, no pre-existing rule applies. This is interests arbitration and the decision will be based on a conception of fairness, or on the relative powers of the two sides in order to make a stable workable agreement. The interests arbitrator is a fast and safe substitute for the bargaining process.

Most of the mathematical theories of arbitration proposed so far have dealt with 
interests arbitration. This paper will present a theory for a problera involving a rights conflict.

Several possible solutions will be presented. Some will reinterpret the problem as one of interests arbitration and solve it using a game-theoretical $m$ :,del, but the solution finally proposed here regards the problem as one of clarifying and reconciling the rights possessed by the parties involved.

The roblem given here has a very specific structure, in which individuals have overlapping rights to a limited transferable commodity. Hopefully our solution can be generalized to a wider range of rights disputes, but we will not try to do this here.

\section{The problem}

The Babylonian Talmud is the great collection of Jewish religious and legal decisions set down during the first five centuries A.D. It includes two kinds of teachings, the Mishnah, which are short statements of the law copied down from the oral heritage of past centuries, and the Gemara, which are commentary on the Mishnah by the rabbis of that time. The book dealing with contracts, leases, sales and found objects, gives the following rule of division.

Two flold a garment... if one of them says, "It is all mine" and the other says, "Half of it is mine",... the former then receives three quarters and the latter receives one quarter (Note 1 , see Section Notes).

(Baba Mezi'a, Fol. 1, Babylonian Talmud, I. Epsicin, ed., 1935)

Around the year 1140 A.D., Rabbi Abraham Ibn Ezra gave a similar problem involving four persons.

Jacob died and his son Reuben produced a deed duly witnessed that Jacob willed to him his entire estate on his death, son Simeon also produced a deed that his father willed to him half of the estate, Levi produced a deed giving him one third and Judah brought forth a deed giving one quarter. All of them bear the same date (Note 2).

(Sefar ha-Mispar, quoted in Rabinovitch, 1973)

The problem is that the wills seem equally valid but are mutually inconsistent in tha: they give away more than the otal estate.

Ho should the estate be divided? It seems fair that sons with larger claims should receive more, but precisely how much more should each get?

A problem of this type, defined by an estate of given size, $n$ heirs and $n$ corresponding wills each specifying a bequest for that heir, which total at least as 
much as the total estate, with each bequest non-negative and less than or equal to the total estate, will be called a simple claims problem. It will be assumed that the heirs' utilities are linear with the amounts they receive.

Rabbi Ibn Ezra describes two possible solutions. The first is to divide the estate in proportion to each son's claim. He attributes this view to the 'gentile sages' but rejects it in favor of a more complicated scheme which he describes as consistent with the teaching of the Talmud (Note 3).

In the next section, Section 3, we will describe Ibn Ezra's solution. His general response to the problem is to specify which particular part of the legacy, which quarter, which third, etc., each son is claiming and he goes on to describe a specific way of doing this. In Ibn Ezra's example one heir claims all the estate, but it is not clear what to do when this is not the case, so in Section 4 his method is extended and justified. In Section 5 modifications of his solution are suggested, still consistent with his general approach. In Section 6 the method of proportional division is discussed pro and con. In Section 7 we state the property of consistency and propose it as a requirement for any acceptable division scheme. A new division scheme satisfying consistency is outlined in Section 8 and discussed in Sections 9 and 10.

\section{Ibn Eara's solution}

Ibn Ezra gives an example in which the total estate is 120 units and the amounts left by each will to each son are as shown in Matrix 1.

Matrix 1 (Total estate 120)

\begin{tabular}{|c|c|c|c|c|}
\hline & Reuben & Simeon & Levi & Judah \\
\hline Will 1 & 120 & - & - & - \\
\hline Will 2 & - & 60 & - & - \\
\hline Will 3 & - & - & 40 & - \\
\hline Will 4 & - & - & - & 30 \\
\hline
\end{tabular}

The figures in Matrix 1 should be understood as fixed in the wills and outside the influence of any of the sons. The wills seem validly dated and there is no suggestion that they were forged.

Ibn Ezra endorses the following solution: divide the estate in proportions $97 / 144$, $25 / 144,13 / 144,9 / 144$. This is approximately $0.67,0.17,0.09,0.06$. He writes,

In accordance with the view of the Jewish sages, the three older brothers say to Judah, "Your claim is only on $30\left(\frac{1}{4}\right)$, but all of us have an equal claim on them. Therefore, take $7 \frac{1}{2}$, which is one quarter and depart". Each one of the brothers takes a similar amount. Then Reuben says to Levii, "Your claim is only on $\mathbf{4 0}(\})$. You have already received your share of the $\mathbf{3 0}$ which all four of us claimed; therefore take $\frac{1}{3}$ of the (remaining) 10 and go". Thus 
Levi's is $10 \frac{\xi}{6}$ (that is, $30 \times \frac{1}{4}$, plus $10 \times \frac{1}{3}$ )... Reuben also says to Simeon, "Your claim is for only half of the estate which is 60 , while the remaining half is mine. Now you have already received your share of the 40 , so that the amount at issue between us is 20 - take half of that and depart". Thus Simeon's share is $20 \frac{5}{6}$ (i.e., $30 \times+$ plus $10 \times \frac{1}{3}$ plus $20 \times \frac{1}{2}$ ) and Reuben's share is $80 \frac{5}{6}$ (i.e., $\left.30 \times \frac{1}{4}+10 \times \frac{1}{3}+20 \times \frac{1}{2}+60 \times 1\right)$.

(Rabinovitch, 1979)

This method is consistent with the teaching of the Talmud in that it yields a division of $(t, t)$ when applied to the problem of the found garment.

\section{I. Analysis of Ibn Ezra's solution}

Ibn Ezra's thinking seems to rest on three premises. He does not state them explicitly, but they are necessary to logic of his argument. The first premise is the following.

Premise PI (Specification of claims). Each son's claim is to a certain specifiable part of" the estate and the problem is to specify which part.

One might think as an alternative that each son could claim only a certain portion of the estat $\varepsilon$ and that there is no way to identify which part the son is claiming. For example, if the claim is to 30 units, then any section of the estate totalling $\mathbf{3 0}$ units is the same as any other in relation to the son's claim. But Ibn Ezra's concept of the claim seems to be different. He portrays one son as saying to another, "You claim 30 but all of us have an equal claim on your 30". In other words the brother's claim is not on some 30 units or other but on an identifiable 30 units.

This premise P1 allows Ibn Ezra to hold the following.

Premise P2 (Nesting of claims). Each larger claim is on a part of the estate that completely contains all smaller claims.

Thus one brother's claim of $\mathbf{4 0}$ completely contains the other's claim of $\mathbf{3 0}$ and so on. This is explicit in the older $b_{1}$ others' statement to the youngest brother, "Your claim is on 30 but all of us have an equal claim on them". One such arrangement of claims is shown in Fig. 1, where the estate is portrayed as being stretched out on a continulum.

But why should this relationstip hold? What is illogical about one brother claiming the first 40 of the 120 and another claiming the final 30 of the 120 , in which case there would be no overlap of their claims? Ibn Ezra gives no argument to support P2, but we will try to devise one in Section 4.

Premise P2 works well only for a certain class of problems, those in which there is one son who claims all of the estate. The example he gives fails in this class, but in 


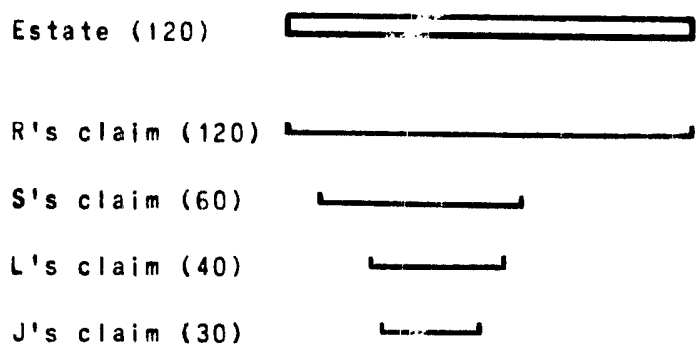

Fig. 1. An arrangement of claims following Ibn Ezra's method.

the general case if one uses his method directly not all of the estate is allotted to the heirs. For instance if there are exactly two sons with claims $80 \%$ and $40 \%$, they will receive $60 \%$ and $20 \%$, respectively. The allocation will not be Pareto-optimal, since the remaining $20 \%$ will not be given out.

We assume that if Ibn Ezra were confronted with the general problem he nould have divided the estate Pareto-optimally and thus he intended P2 to be used only when there is a son claiming all the estate. His method for the more gene.al problem, whatever that method might have been, would imply P2 as a special case. We will take up the question of generalizing the method after we discuss the final implicit premise.

Premise P3 (Symmetrical division). If several brothers claim a certain part of the estate, that part should be divided equally among them.

This seems fully convincing. If the claims on a certait: part of the total are identical, the division of that part should be symmetrical and equal.

Ibn Ezra's first two premises can be regarded as a way of manipulating the problem around until P3 can be applied. They are a way of decomposing any simple claims problem into a set of symmetrical problems. The original problem is expressed as the sum of the subproblems each of the larisi having an obvious solution (Note 4).

\section{Rationale and extension of Ibn Ezra's method}

Suppose we use the approach of trying to minimize the amount of contradiction among the heirs' claims. This requires some way of comparing arrangements for degree of contradiction, and we will propose one now.

We can arrange the claims so that all of the estate is claimed by at least one person but as much of it as possible is not in dispute, i.e., the size of the parts claimed by exactly one heir is maximum. There will be an infinity of arrangements satisfying this so we can apply further restrictions. Within this set, arrange the claims so that as much as possible is claimed by exactly two heirs, rather than three, four or more. 
Although there will be a conflict over this part of the estate, the conflict will involve the fewest number of people. Within the set of arrangements satisfying the restrictions so far, we choose those minimizing the size claimed by exactly three people, exactly four and so on. After $\boldsymbol{n}$ steps we narrow the possible arrangements to a certain set, we choose one and divide the estate according to P3, i.e., parts claimed by severa! heirs are divided equally among them.

This method minimizes the conflict lexicographically according to extent. It tries to avoid disputes over a large section of the estate even though this means many heirs may be fighting over some small parts. Ibn Ezra's P2 is replaced by the following.

Premise Pي' (Lexicographic minimization of conflict by extent). The claims are arranged so that the size of the estate claimed by exactly one heir is maximum, and the size claimed by exactly $i+1$ is maximum given that the size caained by $i$ is maximum, for $i=1, \ldots, n-1$.

Clearly if one heir claims all of the estate, then the claims should be arranged so they are nested, the smaller within the larger, and the division will be identical to ibn Ezra's. It will be called the extended Ibn Ezra method.

A surprising fact is that the division yielded by this method is unique (Appendix A, Theor:m A.1).

This is not the only way to generalize Ibn Ezra's solution, and others have been suggested by $D$. Samet and R. Aumann (private communications) and by an anonymous referee. Our generalization is very favorable to the larger players since the smaller players will tend to nest their claims and fight over the same part of the estate, leaving the rest to the larger players.

\section{Alternatives to $\mathbf{P 2}$}

\section{I. Method of random claims}

Another way to assign each son's claim to a specific part of the estate would be to make the assignments 'at random'. The estate is divided up into small equal parts. Each of the four sons claims some of the parts, the first son claiming all, the second one half of them, the third son oxe third of them and the last son one quarter of them. Each part i; as likely to be rlaimed as any other, independent of the claims of the other sons. After the process is finished, some parts will have been claimed by exactly one, fwo, three, or four sons. Each part is divided equally among the sons claiming it. If some parts happen to be claimed by no one, the entire method is reapplied to those parts, although this would not be necessary for Ibn Ezra's specific problem since the first brother is claiming all of the estate.

Clearly this method retains Ibn Ezra's assumption P1, that claims are on 
specifiable parts and P3, symmetrical division, but it modifies assumption P2, nesting of claims. Now claims overlap one another only to the extent expected by chance.

Applying this to Ibn Ezra's example gives the fractions to the four brothers as $165 / 288,59 / 288,37 / 288,27 / 288$ or approximately $0.57,0.21,0.13,0.09$. These values are shown in Table 1 for comparison with other methods. Details of the calculations are in Appendix B.

Table 1

Fractions allotted by division schemes

\begin{tabular}{lcccccc}
\hline & \multicolumn{3}{c}{ Problem of wills } & \multicolumn{2}{c}{ Problem of garment } \\
& $\begin{array}{c}\text { Reuben } \\
(1)\end{array}$ & $\begin{array}{c}\text { Simeon } \\
\left(\frac{1}{2}\right)\end{array}$ & $\begin{array}{c}\text { Levi } \\
\left(\frac{1}{4}\right)\end{array}$ & $\begin{array}{c}\text { Judah } \\
\left(\frac{1}{4}\right)\end{array}$ & 1 & $\vdots$ \\
\hline Talmud & - & - & - & - & 0.750 & 0.250 \\
Ibn Ezra's method & 0.674 & 0.174 & 0.090 & 0.063 & 0.750 & 0.250 \\
Random claims & 0.573 & 0.205 & 0.128 & 0.094 & 0.750 & 0.250 \\
Non-cooperative game & 0.486 & 0.241 & 0.157 & 0.116 & 0.750 & 0.250 \\
Bargaining game & 0.516 & 0.227 & 0.145 & 0.111 & 0.750 & 0.250 \\
Proportional division & 0.480 & 0.240 & 0.160 & 0.120 & 0.667 & 0.333 \\
Recursive completion & 0.479 & 0.243 & 0.160 & 0.118 & 0.750 & 0.250 \\
\hline
\end{tabular}

The first brother's advantage is substantially reduced now that claims are placed randomly over the estate. His allocation drops from $67 \%$ to $57 \%$.

Unfortunately the method of random claims has a serious flaw. In problems where the wills are consistent with each other, it does not divide the estate in the way directed by the wills. For example, if the will leaves $80 \%$ and $20 \%$ to the two heirs, the method of random gives them $86 \%$ and $14 \%$. We could avoid this by amending the method with a special rule for the case that the wills are consistent, but then the method would not be monotonic. Two wills allotting $80 \%$ and $20 \%$ respectively to the two heirs would result in a share of $20 \%$ to the second heir, but wills of $80 \%$ and $25 \%$ would decrease the second person's share to $18 \%$.

\subsection{The claims problem as a non-cooperative game}

Another alternative to assumption P2 is that the court direct the four sons themselves to specify which parts of the estate they are claiming. After their claims are received the court divides each part among those who want it.

This is a game of strategy among the four brothers. A strategy in the game involves choosing some particular portions of the estate of proper total size and laying a claim to them. The payoffs are determined by the court's application of premise P3. Of course the game need not be played - the court may decide to calculate what the outcome would be for rational players based on some solution theory and allot the brothers that division.

To define the game completely we must specify what possibilities are available for 
communicating, making believable threats and making binding agreements.

If no sommunication whatsoever is allowed, then all strategies would appear alike to a brother and he would have no reason to choose one over another. This leads back to the method of random claims outlined previously.

Alterstatively, if the players can communicate but cannot make enforceable threats or agreements, the traditional theory of games would predict they would choose a Nash equilibrium. There is not a unique Nash equilibrium in this game and the 4-tuples of strategies which are Nash equilibria will in general result in different payoff vectors. The set of payoffs for the Nash equilibria is a closed simplex brounded by an equilateral triangle with vertices

$$
\begin{aligned}
& \text { (70/144, 36/144, 22/144, 16/144), } \\
& \text { (70/144, 34/144, 24/144, 16/144), } \\
& (70 / 144,34 / 144,22 / 144,18 / 144) \text {. }
\end{aligned}
$$

Since this region is symmetrical and very small relative to the total set of possible payoffs, we will choose the centre of the triangle, which is 105/216, 52/216, 34/216, $25 / 216$ or approximately $0.49,0.24,0.16,0.12$, as a typical point representing the division based on Nash equilibrium theory. Calculations are described in Appendix B.

Note that the first brother's share is reduced even further than that in Ibn Ezra's method and the random claims method. This is not surprising. Here all brothers are given the ability to make strategic choices when they place their claims, but this is no advantage to the first brother, since he still has only one choice, to claim all of the estare. Only the weaker brothers are given a wider choice, and consequently they gain in the final division.

The arrangements resulting from the use of Nash equilibrium strategies show a constant pattern, as described in Appendix B. A typical arrangement of claims is shown in Fig. 2(a). In this arrangement the total size of the parts of the estate claimed by all four brothers is minimal. Given that this is minimal, the size of the parts claimed by three brothers is minimized, etc.

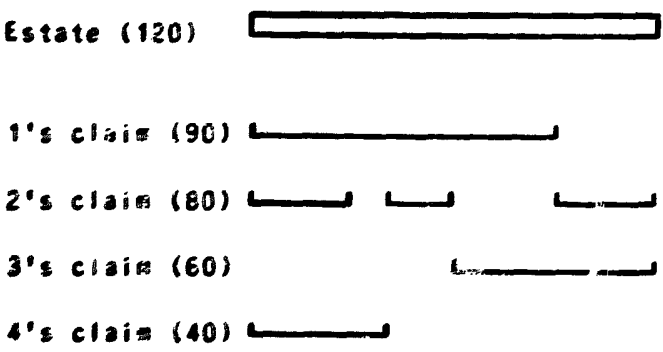

(a)

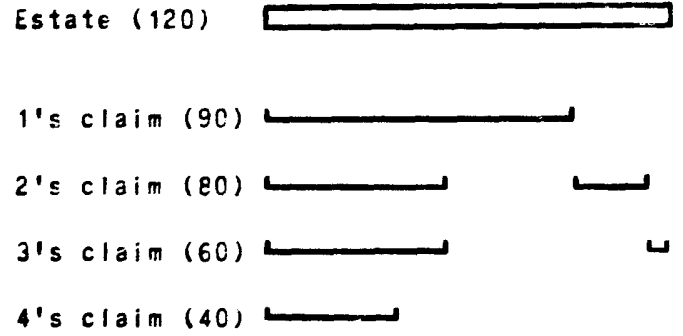

(b)

Fig. 2. (a) An arrangement of claims that is a Nash equilibrium. (b) An arrangement of claims by the extended Ibn Ezra method. 
A Nash equilibrium division is like the extended Ibn Ezra method of Section 4, in that it minimizes the conflict lexicographically, but in one sense it is the dual of the extended lbn Ezra method. Whereas the latter paid primary attention to the exteni of the conflict, i.e., tried to arrange claims so that very little of the estate was in dispute, Nash solutions pay attention to intensity - how many heirs are fighting over some part of the estate, whatever the part's size. Also, unlike the extended Ibn Ezra method, the Nash outcome is not unique.

\subsection{The claims problem as a cooperative game}

Another approach would be to regard the problem as a full-fledged cooperative game. The players can communicate with each other, can threaten and bargain, all four at a time, or in any subset of the four. Ibn Ezra's problem then becomes a nonsimple bargaining game with transferable utility, using the terminology of Harsanyi (1978), who has proposed a solution method for such games. Details of its application to our problem are given in Appendix B. The players receive 223/432, $98 / 432,63 / 432,48 / 432$, or approximately $0.52,0.23,0.15,0.11$.

\section{The method of proportional division}

\section{Rabbi lbn Ezra writes,}

The gentile sages would divide the estate in accordance with the ratio of the face value of each, while the Jewish sages divide it in proportion to each one's claim. Thus the mathematicians (i.e., the gentile sages) say that the amount is one and when you add to it! plus $\frac{1}{3}$ plus $\frac{1}{4}$, the sum is $2 \frac{1}{12} \ldots$ In short, Simeon take: half of Reuben's share, and Levi one third of Reuben's share and Judah one fourth of Reuben's share.

(Sefar ha-Mispar, quoted in Rabinovitch, 1973)

The sons are thus receiving a share proportional to their claim. The division is $12 / 25,6 / 25,4 / 25,3 / 25$ or $0.48,0.24,0.16,0.12$.

This seems straightforward and easy to calculate, but can anything more be said to support it? One advantage is shown by the following example.

Suppose the fourth brother were to die and leave two heirs. One might expect his heirs to have equal claims of $\frac{1}{8}$ and $\frac{1}{8}$ to replace his claim of $\frac{1}{3}$. The original problem with four claims $\left(1, \frac{1}{2}, \frac{1}{3}, \frac{1}{4}\right)$ might be replaced by a five-claim problem $\left(1, \frac{1}{2}, \frac{1}{3}, \frac{1}{8}\right.$, $\left.\frac{1}{8}\right)$. It seems reasonable that the other three sons' shares should not change because of the death of the fourth son and clearly with the method of proportional divisions they would not.

Alternatively, suppose two of the sons were able to form a partnership and 
present a deed for the total of their two claims. For example, the third and fourth sons join together and change the original claims problem to a three-person problem with claims $\left(1,1, \frac{7}{12}\right)$. (The two sons have agreed to split up the gain in some specified way after the court has decided their total share.)

We would hope that such manipulation would not work and that the two sons' total share would be independent of any coalition they form. In fact, there is no temptation to form coalitions if the method of proportional division is used. Theorem C. 1 in Appendix C shows that proportional division is unique in this respect. It is the only method that is (1) symmetrical, i.e., it is independent of the numbering of the heirs; (2) continuous at at least one point, regarding a son's allotment as a function of his claim (Note 5); (3) efficient in the sense of distributing all of the estate; (4) independent of the ardition of dummy heirs with zero claims and (5) strategy-proof in the sense outlined above.

This argument for proportional division seems attractive but not completely convincing. The strategy-proofness property is an advantage only if such strategies are allowed. The court might simply refuse to regais :he two grandsons as fullNedged claimants to the inheritance and might insist ot etling the question in two steps, first as a four party problem where the grandsons are regarded as one, and next as a problem of division between the grandsons.

A dis sdvantage of proportional division from Ibn Ezra's viewpoint is that it is inconsistent with the Talmud. It results in the found garment being divided $\frac{2}{3}, \frac{1}{3}$. (All the other methods presented so far are consistent with the proportions in the Talmud, as shown in the right column of Table 1.)

\section{The requirement of consistency}

We have seen that Ibn Ezra looked upon the claims problem as a question of stating which partizular parts of the estate were being claimed by each heir. The wills themselves state only the total proportions claimed by each, so in effect he was trying to read between the lines, to deduce more information from them than they explicitly state.

The method proposed in this section also tries to deduce more specific information from the wills, but in another way. As it stands each will mentions a single brother. We will try to infer what proportion each will is implicitly leaving to the other three brothers.

This approach will not determine a division of the estate exactly but it will restrict possible division schemes to a nart ow set. In fact, all the methods proposed so far will be eliminated.

Instead of constructing a division scheme, we will assume we already have one in mind. This scheme, which will be labeled $d$, is a general rule for solving simple clatms problems. The procesure $t:$ be given now is a way of testing $d$ for selfconsistency, and possibly rejecting it (Note 6). 
For certain claims problems, any division method $d$ will not only give a division of the estate, it can also solve the question of how to fill in the blanks in each will, i.e., how to determine the amounts implicitly left to the heirs not mentioned in the will. The reason is that in certain problems, filling in the blanks is itself equivalent to a simple claims problem. (An illustration of this will be given shortly.)

Suppose we were able to fill in the blanks so that all wills stated what each son should receive. Each will is assumed to have been completed in some reasonable way, each giving away the total estate (although the wills still contzadict each other, of course). It would then be clear how to divide the estate. No will has any more validity than any other, so it should be assumed that each is equally likely to be right and has equal reason to be adopted. Thus each person should be given his expectation, i.e., the average of the values appearing in the four wills.

For certain claims problems and a division method $d$ we now have two ways of calculating a solution based on $d$.

(1) Apply $d$ to the problem directly.

(2) Use $d$ to fill in the blanks in each will and solve by averaging.

A division method is consistent if the two calculations give identical results.

For example, suppose we believe in the method of proportional division and choose it as our favored method, $d$. We are presented with the problem shown in Matrix 2.

Matrix 2 (Set of heirs $N=\{1,2,3\}$, total estate 18)

Heirs
Will 1
Will 2
Will 3 $\quad\left[\begin{array}{ccc}1 & 2 & 3 \\ - & 6 & - \\ - & - & 6\end{array}\right)$

Applying proportional division directly, as in approach (1), gives $9,4 !, 4 !$.

Using the second approach, how should the wills be filled in? In the case of will 3, what claims should we regard it as implicitly assigning to heirs 1 and 2 ?

Given that will 3 has already allocated 6 , there are $18-6=12$ units left for heirs 1 and 2 . The two heirs can present claims on this 12 , for 12 and 6 units, respectively, based on wills 1 and 2 . Will 3 does not regard these claims as totally invalid, but insists only that 6 units be granted to heir 3 . So, will 3 regards the other two claims as limited to the 12 remaining units of the estate. This is the simple claims problem specified in Matrix 3.

Matrix $3(N=\{1,2\}$, total estate 12$)$

Heirs
Will 1
Will 2 $\quad\left(\begin{array}{cc}1 & 2 \\ 12 & - \\ - & 6\end{array}\right)$

Since proportional division has been assumed to be the proper solution method, we can use it to solve this problem and allot 8 and 4 to heirs 1 and 2, respectively. 
These are the amounts will 3 is implicitly leaving to heirs 1 and 2, so that will 3 may be changed from $(-,-, 6)$ to read $(8,4,6)$.

Note that heir 3 still has a bequest of 6 units, just as in the original incomplete version of will 3. Our aim here is not to revise or correct existing parts of will 3 , but to fill in the unspecified parts. We cannot raise or lower the amount allocated to heir 3, since this has already been specified.

Applying similar reasoning to complete the other two wills, yields $(12,3,3)$ for will $I$ and $(8,6,4)$ for will 2 . Solving by averaging each heir's claim over the three wills gives a division of $(9\}, 4\}, 4\})$.

This is different from the solution using proportional division directly which was $(9,4 !, 4 !)$. The direct and indirect modes of solving the problem should agree with each other, but do not. Consequently, our mistake must lie in our original assumption that proportional division is the correct method.

This argument is outlined in Fig. 3.

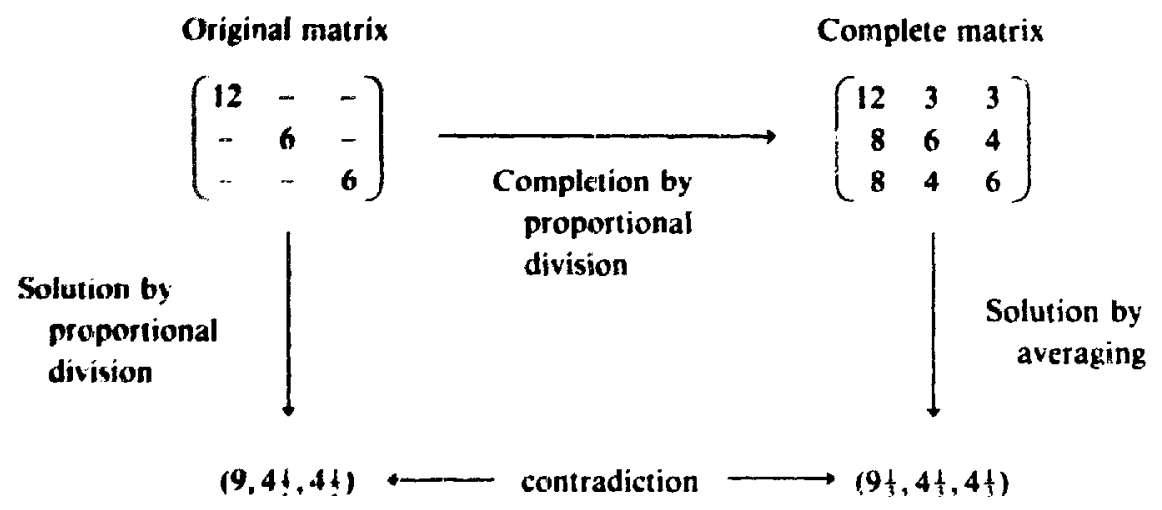

Fig. 3.

The other methods stated above (!bn Ezra's method, random claims, sclution as a non-cooperative or cooperative garue) are also not consistent as can be verified by applying each to Matrix 2.

\section{The method of recursive completion}

The method to be proposed nov satisfies the requirement of consistency and also has a simple dynamic interpretation.

It involves two steps. First, for each of the $\boldsymbol{n}$ wills, a claims problem is defined whose solution would allow us to complete the will. It is as follows: let the original $n \times n$ claims matrix be $C$, the total estate be $t$, and will $i$ assign claim $c_{i}$ to heir $i$. Then we construct the claims problem with the $(n-1) \times(n-1)$ matrix $C_{i}$, the submatrix of $c$ found by deteting will $i$ and heir $i$. The new claims problem is defined as having total estate $t_{i}=t-c_{i}$, as in Matrix 3. 
This may or may not be a simple claims problem as defined in Section 2. It will not be simple if someone claims more than the possible total $t_{i}$. It is easy to show that if someone claims more than the total possible, then after the matrix is completed and the bequests are averaged, the resulting division will be more than the amount available. Therefore, we must alter the matrix $C_{i}$ to make it a simple claims problem. The obvious way is to define a matrix $C_{i}^{\prime}$ in which any claim in $C_{i}$ which is more than $t_{i}$ is replaced by a claim of exactly $t_{i}$, so that the heirs are not allowed to claim more than the total estate. If they do, their claims are truncated.

For each will in $C_{i}^{\prime}$ a set of $(n-2) \times(n-2)$ claims problems is generated in turn whose solutions will allow the completion of $C_{i}$. This procedure is followed recursively. Eventually we arrive at a list of problems with only one claimant each.

Stage two of the method consists of solving each smaller claims problem and using the solution to fill in the blanks in the next larger problem. For the smallest problems, those with only one claimant, the claim and the total estate available will both equal $\max \left(t-\sum_{i \in N-\{j\}} c_{i}, 0\right)$, where heir $j$ is the single claimant. The solution is obvious, that heir $j$ takes whatever is available. Each $k \times k$ problem is solved and used to fill in some of the blanks of the $(k+1) \times(k+1)$ matrix that generated it in stage one. Once the latter matrix is complete its solution can be found by averaging and it is used to complete a matrix of the next larger size. Eventually we arrive at a solution of the original matrix.

The final solution will be feasible and efficient, that is, it will give away exactly all of the estate. This can be shown by recursion: the one-claimant problems are feasible and efficient and if a $k$-claimant problem is feasible and efficient, then so is the $(k+1)$-size problem that generated it.

The method of recursive completion is applied to Ibn Ezra's problem in Figs. 4 and 5. The total estate available appears to the upper left of each matrix. Arrows indicate the flow of the calculations.

As an example we will follow the computation involving the two starred matrices. We wish to fill in will 3 in the original matrix, to determine what it is implicitly leaving to heirs 1,2 and 4.

After $\mathbf{4 0}$ units have been transferred to heir $B$, there would be 80 left for the other three heirs. Based on wills 1,2 and 4 these heirs are claiming 120,60 and 30 . The first claim of 120 cannot be allowed so it is truncated to 80 . This is the claims problem shown in the second starred matrix and its solution will allow us to fill in the blanks in will 3. It is solved in like manner, by generating a number of smaller problems as shown in Fig. 4.

In Fig. 5 the smaller problems have been solved and the starred matrix is filled so it is complete and solvable by averaging. It yields $115 / 3,85 / 3$ and $40 / 3$ to heirs 1,2 and 4, respectively. These values are inserted in will 3 in the original matrix, and along with the other values this gives the solution as $57 \frac{1}{2}, 29 \frac{1}{6}, 19 \frac{1}{6}, 14 \frac{1}{6}$.

The four sons receive fractions $69 / 144,35 / 144,23 / 144$ and $17 / 144$ or approximately $0.48,0.24,0.16$ and 0.12 . The method gives slightly less to the first son than does proportional division, although this is disguised due to rounding off. 


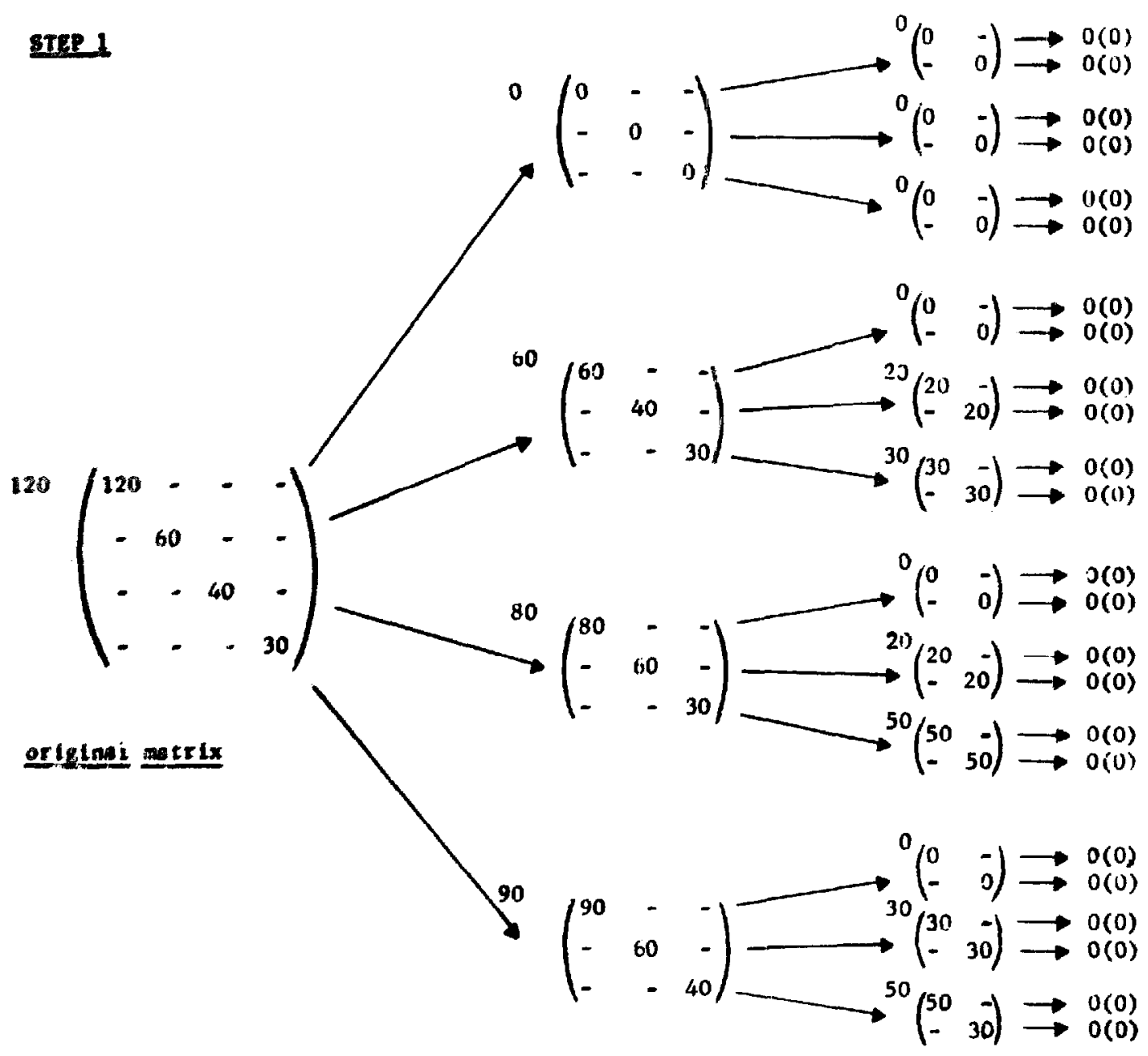

Fig. 4. The method of recursive completion applied to Ibn Ezra's problem:

Step 1 , generation of subproblems.

The method of recursive completion can be given a dynamic interpretation. Suppose the claims problem is solved by holding a race. The brother who arrives at court first has his claim satisfied, since no other claims have been presented. The next brother is satisfied with as much of the estate as is left, and so on, each arrival receiving his claim or part of his clain until the estate is exhausted. Instead of actually holding such a race, we could give the brothers what they would expect to receive: if all orders of arrival were qually likely.

Clearly this would give the same solution as the method of recursive completion, since after the first person has been paid off the problem becomes a race among a reduced set of brothers for a reduced payoff in just the manner specified in the method of recursive completion.

This dynamic interpretation shows the close connection between this solution method and the Shapley value for $n$-person games, which can be modelled in a very similar way. It also gives a way of calculating the solution that is easier than Figs. 4 
STEP 2
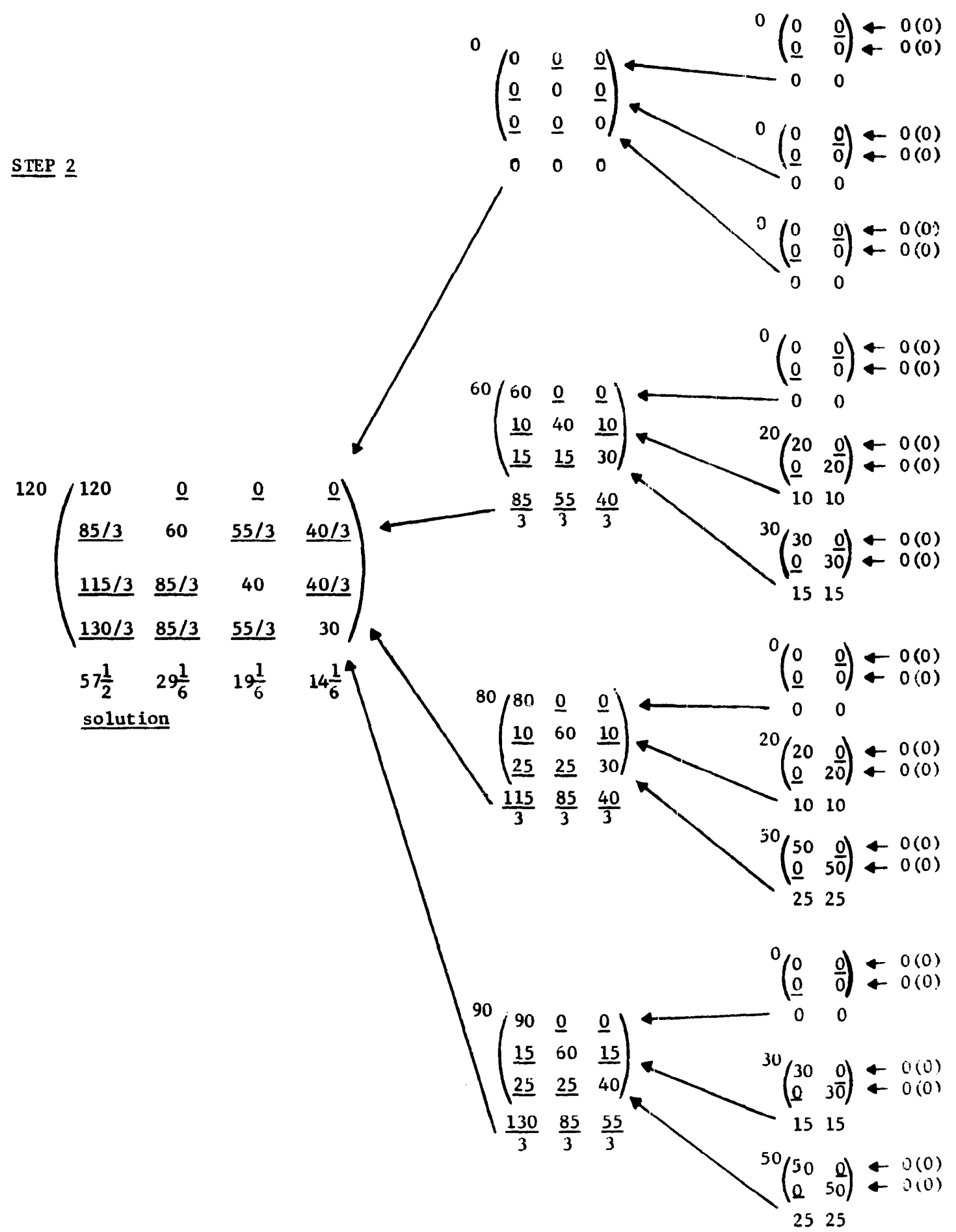

Fig. 5. The method of recursive completion applied to Ibn Ezra's problem: Step 2, solution of subproblems by averaging. Values determined by solving smaller problems are underlined. Solutions appear below each matrix. 
and 5: list all possible orders of arrival and for each one, calculate the amount each heir would receive, and take the average of these for a given heir. In certain cases a fast way of calculating the Shapley value (Mann and Shapley, 1962) can be modified and used.

The model of a race entails the following formula for heir $i$ 's share, $x_{i}$,

$$
x_{i}=\sum_{s \mid i \in \text { s } s} \frac{s !(n-s-1) !}{n !} b_{i}
$$

where $c$ is heir $i$ 's claim, $t$ is total available, $s=|S|$, and

$$
b_{1}= \begin{cases}c_{t} & \text { if } t-\sum_{\epsilon \in S} c_{j}>c_{i}, \\ t-\sum_{j \in S} c_{j} & \text { if } c_{i} \geq t-\sum_{j \in S} c_{j} \geq 0, \\ 0 & \text { if } 0 \geq t-\sum_{j \in S} c_{j} .\end{cases}
$$

The method can also be derived from a bargaining model of the claims process. For a given coalition of heirs $S$, suppose the complementary coalition has claims totallim. $t_{N-s}=\sum_{\in \in N}-s c_{i}$ where $c_{i}$ is the claim of heir $i$. Then if $t_{N-s}<t, N-S$ has no claim over the amount $t-t_{N} . s$ and there can be no objection to the court granting this to coalition $S$. This suggests defining a characteristic function game

$$
v(S)=\max \left(t-\sum_{i \in N-S} c_{j}, 0\right) \text { for } S \subseteq N .
$$

This function $v$ ignores soine relevant parts of the original problem since $v(S)$ is not the amount. $S$ is actually claiming, which may be a good deal more. In any case the garee is well defined and we can calculate its Shapley value as a reasonable solution.

The Shapley value of this game for heir $i$ is

$$
\varphi_{1}=\sum_{S, \in S_{S}:} \frac{(s-1) !(n-s) !}{n !}(v(S)-v(S-\{i\})) .
$$

The term $v(S)-v(S-\{i\})$ can be shown to equal

$$
\begin{cases}c_{t} & \text { if } t-\sum_{\in \in N-s} c_{j} \geq c_{i}, \\ 1-\sum_{\epsilon \in S} c_{j} & \text { if } c_{i} \geq t-\sum_{, \in N-s} c_{j} \geq 0, \\ 0 & \text { if } 0 \geq t-\sum_{, \in N \cdot s} c_{j} .\end{cases}
$$

By changing the variable of summation in the formula for $\varphi_{i}$ from $S$ to $N-S, \varphi_{i}$ is shown to equal $x_{i}$, the share by recursive completion.

these two dynamic interpretations of recursive completion are interesting, but the most substantial support comes from the original justification, namely, that it results from completing the blanks in the wills in a sensible way. 


\section{Generalizations of Ibn Ezra's problem}

Ibn Ezra included the same number of wills as heirs, but there is no reason why the problem should be restricted in this way. If there are fewer wills, and each will specifies a bequest for one heir, we can drop out the heirs who are not named in any will, the claim matrix will become square and the problem will become a simple claims problem.

If there are more wills than heirs, so that one heir appears in several wills, then the method of recursive completion can be applied without modification. Nothing in its justification relied on the numbers of wills and heirs being equal.

Problems of this type, which would be simple except that there are more wills than heirs, will be called rectangular claims problems.

It is not obvious how any of the other methods would be generalized to deal with rectangular claims problems. The method of proportional division, for example. seems to depend on each heir having exactly one claim to the estate.

A broader class of problems, exemplified in Matrix 4 allows one to name several heirs. This will be called a general claims problem.

Matrix $4(N=\{1,2,3\}$, total estate 12)

$$
\left[\begin{array}{ccc}
- & - & 7 \\
6 & 4 & - \\
- & - & 6 \\
4 & - & 8
\end{array}\right]
$$

A situation like this arises if three people find a garment and some claim to have found it with some of the others. This was discussed first apparently in the last century by an anonymous Talmudic scholar working in Jerusalem ("Sage of Jerusalem", 1887).

The method of recursive completion cannot be applied to such problems directly since it gives us no rules to follow if two claims in the same will are made on the same amount of estate. Some generalization of the method is necessary, but we will not pursue this question here.

\section{Comparison of methods}

The six division methods presented are:

Method 1, Ibn Ezra's method, and its generalization;

Method 2, random claims;

Method 3, claiming parts of the estate in a non-cooperative game;

Method 4, claiming parts of the estate in a bargaining game;

Method 5, proportional division.

Ibn Ezra's method does not give any results that violate our conception of fairness, as far as we have found, so its acceptability rests on the acceptability of its 
premises, especially the idea of nesting of claims. We have given one rationale for this, and it would be interesting to know if there are others.

Method 2, random claims, sometimes does not dispose of all the estate, which is a fatal flaw. Methods 3 and 4, the game-theoretical models, share two features. First, they tend to take the approach of interests arbitration, asking in effect what would the outcome be if there were no arbitrator to settle the dispute. Seund, they accept Iton Ezra's premise PI that we must specify who is claiming what parts of the estate. Anyone who finds these two features appealing on philosophical grounds may favour one of these methods.

It should be clear that we do not find the first feature appealing. We believe a theory of rights arbitration is possible and appropriate here. We also note that there are many other assumptions that could be made about the possibilities of cooperation and threats, if the heirs were to be regarded as playing a game. It seems to be arbitrary whether Method 3 or Method 4 or any of the many intermediate possibilitics allowing partial communication or enforceability is chosen as the proper way to solve the conflict.

Proportional division, Method 5, takes no position on what the claims in the wills 'really mean', and in this way makes itself less vulnerable to objections. It is a simple method and it is also strategy-proof, although we have given reasons to sugent that strategy-proofness is not especially compelling in this context. Also, it cannot deal with rectangular claims matrices. Nor can any of the other methods, $1-4$, as far as we can see.

The method of recursive completion strikes us as reasonable. general and relatively free from arbitrary assumptions. Recursive completion belongs with Ibn Ezra's original method in the category of pure rights arbitration. Just as a dispute over loafing on the job would be solved by clarifying the meaning of the term loafing, these two methods try to clarify the meaning of the wills. Interests or benefits are not involved. In this way they show that rights arbitration, like interest arbitration, is open to mathematical treatment.

The method of recursive completion takes an approach to rights arbitration analogous to the approach of game theory to interests conflicts. In the theory of games the players put themselves in each others' shoes and look at the conflict from the opposite viewpoint. The method of recursive completion takes the attitude that the parties should not simply reiterate their own rights but try to clarify what rights they see the others as possessing in the situation, which we termed 'filling in the blanks'.

This is a very general principle ci conflict resolution and hopefully it can guide us to extend the types of rights problems solvable by mathematical means.

\section{Apisendix A. Uniqueness of extended Ibn Ezra method}


representing the size of each heir's claim, such that $0 \leq c_{i} \leq t$ and $\sum c_{i} \geq t$.

If the heirs claim parts of the estate of sizes c, such that

(1) the size of the part of the estate claimed by exactly one heir is maximal.

(2) for fixed size of the part of the estate claimed by no more than $\alpha-1$ heirs, the size of the estate clained by $\alpha$ heirs is maximal for $\alpha=2, \ldots, n$, and if $x$ is the allocation to the heirs determined by dividing each part equally among its claimants, then $x$ is unique.

Proof. We will asstime that the heirs are numbered so that the claims $c_{1}$ are in decreasing order.

If one heir claims all of the estate it is clear what arrangement is required by the conditions of the theorem: the claims must be nested as in Ibn Ezra's method and the allocation $x_{i}$ will be uniquely ditermined, so it will be assumed that no one claims the whole estate, i.e., $c_{i}<t$ for all $i$.

For convenience, we define $c_{i}=0$ for $i>n$.

We will let $T$ be the total estate, so that $|T|=t$, and call a vector $C=\left\{C_{1}, \ldots, C_{n}\right\}$ an arrangement of claims if $C_{i} \subseteq T$ and $\left|C_{i}\right|=c_{i} .\left(C_{i}\right.$ are goods or commodities. They are sets of entities, not to be confused with the matrices $C_{1}$ introduced elsewhere.) Vector $A=\left\{A_{0}, A_{1}, \ldots, A_{n}\right\}$ is defined to be the parts of the estate claimed by exactly $0,1, \ldots, n$ heirs.

It will first be shown that if an arrangement $C$ satisfies the conditions of the theorem it must have the following properties.

(i) Every positive-sized part of the estate is claimed by some heir, i.e., $A_{0}=\boldsymbol{0}$.

(ii) If an heir $i$ claims a positive-sized part of $A_{1}$, then $i$ will claim all of $A_{\alpha}$ for $\alpha \geq 2$.

(iii) If an heir $i$ claims a positive-sized part of $A_{\alpha}$, then $i$ will claim all of $A_{\beta}$ for $\beta \geq \alpha \geq 2$.

The first property (i) follows directly from condition (1) of the theorem along with the requirement $\sum c_{i}=t$.

The second property (ii) can be proven by contradiction. We assume that $\boldsymbol{C}$ does not satisfy (ii) and use this to generate another arrangement $C^{\prime}$ that is higher :a the ordering implied by (1) and (2) of the theorem.

Following this line, suppose there is a positive-sized part of $A_{1}$ claimed by heir $i$ and also a positive-sized part of $A_{\alpha}$ not claimed by $i$ for some $\alpha \geq 2$. Let $j$ be an heir who claims some of $A_{a}$ not claimed by $i$. In set notation we have $A_{1} \cap C_{l}>0$ and $\left|A_{\alpha} \cap\left(T-C_{i}\right) \cap C_{j}\right|>0$. Let $b$ be some positive number smaller than either of these two sets, and choose three sets:

$D_{1}$ - a part of $C_{i} \cap A_{1}$ of size $b / 2$.

$D_{2}$ - a part of $C_{j} \cap\left(T-C_{i}\right) \cap A_{\alpha}$ of size $b / 2$.

$D_{3}$ - a part of $C_{j} \cap\left(T-C_{i}\right) \cap A_{\alpha}$ of size $b / 2$ disjoint from $D_{2}$.

We can define $C^{\prime}$ based on $C$ as follows. Remove $i$ 's claim on $D_{1}$ and instate it on $D_{2}$; remove $j$ 's claim on $D_{3}$ and instate it on $D_{1}$.

Arrangement $C^{\prime}$ will be consistent with the vector $c$. Only the values $A_{a+1}$ and 
$A_{a-1}$ are altered by the change and $A_{i-1}$, the part claimed by exactly $\alpha-1$ heirs, will be reduced by amount $b / 2$, so that $C$ could not have been maximal as defined by (1) and (2) of the theorem, contrary to our assumption.

Property (iii) is shown in the sarne way. Assume there are heirs $i$ and $j$ and parts $A_{\alpha}$ and $A_{\beta}$ with $\beta \geq \alpha \geq 2$ such that $\left|A_{\alpha} \cap C_{i}\right|>0$ and $\left|A_{\beta} \cap\left(T-C_{i}\right)\right|>0$, contrary to (iii). Let $j$ be an heir claiming some of $A_{\beta} \cap\left(T-C_{i}^{\prime}\right)$. Choose a small number $b$ and let $D_{1} D_{2}$ be as follows.

$D_{1}$ - a part of $A_{\alpha} \cap C_{i}$ of size $b$,

$D_{2}$ - a part of $A_{\beta} \cap\left(T-C_{i}\right) \cap C_{j}$ of size $b$.

Generate a new arrangement $C^{\prime}$ by transferring $i$ 's claim on $D_{1}$ onto $D_{2}$ instead, and $j$ 's claim on $D_{2}$ onto $D_{1}$. The size of everyone's claim is unaltered, only $A_{\alpha+1}$ and $A_{\alpha-1}$ are changed and $A_{\alpha-1}$ is decreased by $b$, so that $C^{\prime}$ is higher on the ordering inplied by (1) and (2) of the theorem, contrary to the assumption.

Arrangements satisfying (1) and (2) of the theorem and thus (i), (ii) and (iii) can be described in a simple way. Consider those heirs who claim some of $A_{1}$. These wil! be the largest heirs since their claims must contain the claims of those heirs who dc not ciaim part of $A_{1}$, by (ii). Let there be $j^{*}$ heirs who claim a part of $A_{1}$. The number $j$ * must be 2 or greater, since if $j^{*}=1$, that heir's claim would contain all smaller claims but no o.s. claims all of $T$. Eacti of their claims can be divided into two parts. For $i=1$ to $j^{*}$, part of $C_{i}$ is claimed by heir $i$ alone, and the rest of $C_{i}$, call it $C^{*}$, is claimed by all of these $j^{*}$ heirs, by (ii). The other heirs, from $j^{*}+1$ to $n$ will have claims that lie entirely in $C^{*}$, by (ii), and their claims will be nested successively, by (iii).

To specify the allocations $x_{i}$ it is necessary only to determine the number $j^{*}$ and the size of $C^{*}$. Given these we can completely specify the patterns of overlap of all the ciaims using the above description of the arrangement, and thus calculate $x_{i}$.

Letting $c^{*}=\left|C^{*}\right|, c^{*}$ and $j^{*}$ are related in that the claims of the first $j^{*}$ heirs completely cover the estate: $C_{1} \cap \cdots \cap C_{j *}=T$. Since the claims overlap on part $C^{*}$, we have

$$
\sum_{i=1}^{\infty} c_{i}-\left(j^{*}-1\right) c^{*}=t
$$

Since $C^{*}$ contains all claims smaller than $C_{j}$ but is a part of $C_{j *}$,

$$
c_{j}>c^{*} \geq c_{j *+1}
$$

(1) and (2) are necessary conditions on $c^{*}$ and $j^{*}$. It will be shown that they define $c^{*}$ and $j^{*}$ uniquely.

Define the following function of $j$ for $j \geq 2$,

$$
g(j)=\left(\sum_{i=1}^{j} c_{i}-t\right) /(j-1)
$$

According to (1) and (3), $g(j)$ would be the size of $C^{*}$ if $j=j^{*}$.

The values of $j$ can be partitioned as follows. 


$$
\begin{aligned}
& N_{1}=\left\{j \mid c_{j}, c_{j+1}>g(j)\right\}, \\
& N_{2}=\left\{j \mid c_{j}>g(j) \geq c_{j+1}\right\}, \\
& N_{3}=\left\{j \mid g(j) \geq c_{j}, c_{j+1}\right\} .
\end{aligned}
$$

Thus to show that $j^{*}$ is unique it is sufficient to show that exactly one value of $j^{*}$ is in $N_{2}$.

First, it is clear that $j=2$ is in $N_{1}$ or $N_{2}$ since $c_{1}<t$, hence

$$
c_{2}>0>c_{2}-\left(c_{1}-t\right)=g(2) \text {. }
$$

If a given $j$ is in $N_{3}, j+1$ will be in $N_{3}$ for the following reasons. If $j \in N_{2}$, then $g(j) \geq c_{j+1}$ and thus

$$
\sum_{i=1}^{j} c_{i}-t \geq c_{j+1}(j-1) \text {. }
$$

By adding $c_{j+1}$ to each side and dividing by $j$ we have $g(j+1) \geq c_{j+1}$, and since also $c_{j+1} \geq c_{j+2}$, it follows that $j+1$ will be in $N_{3}$. Also, if $j$ is in $N_{3}, j+1$ will be in $N_{3}$, since from $g(j) \geq c_{j}$ we have

$$
\sum_{i=1}^{j} c_{i}-t \geq c_{j}(j-1) \text {. }
$$

Adding $c_{j+1}$ to each side gives

$$
\sum_{i=1}^{j+1} c_{i}-t \geq c_{j}(j-1)+c_{j+1}
$$

Thus the left-hand side is greater than or equal to $c_{j+1}(j)$. Dividing by $j$, we have $g(j+1) \geq c_{j+1}$, and since aiso $c_{j+1} \geq c_{j+2}, j+1$ is in $N_{3}$.

Finally, $j=n$ is in $N_{2}$ or $N_{3}$ since $g(n)$ is positive but $c_{n+1}=0$.

Thus $j$ starts out in $N_{1}$ or $N_{2}$ for $j=2$. If $j$ enters $N_{2}$ it immediately passes to $N_{3}$ and ends up in $N_{2}$ or $N_{3}$ when $j=n$. It follows that $j$ is in $N_{2}$ at exactly one value, which will be $j^{*}$.

This unique value of $j^{*}$ can be found by successively checking the values of $j$ until (1) and (2) are satisfied. The allocations $x_{i}$ are determined by finding $c^{*}$ from (1), constructing an arrangement $C$ according to (i), (ii) and (iii) and calculating the allocations to the heirs by

$$
x_{i}=\sum_{\alpha=1}^{n}\left|A_{\alpha} \cap C_{i}\right| / \alpha
$$

\section{Appendix B. Calculation of the solutions}

\section{B.1. Random claims}

Let $c_{i}$ be the amount of heir $i$ 's claim and let $p_{i}=c_{i} / t$ be the proportion heir $i$ is 
claiming. Let $x_{i}$, which is to be determined, be the amount awarded to heir $i$ by the method of random claims.

Then $x_{i}$ is equal to the amount heir $i$ receives from that part of the estate claimed by himself alone, plus the amount from the part claimed by himself and one other person, etc., plus the amount yielded when the process is reapplied to any part claimed by no one.

For example, for heir 1 ,

$$
\begin{aligned}
x= & t p_{1}\left(1-p_{2}\right)\left(1-p_{3}\right)\left(1-p_{4}\right) \\
& +\frac{1}{2} t p_{1}\left[p_{2}\left(1-p_{3}\right)\left(1-p_{4}\right)+p_{3}\left(1-p_{2}\right)\left(1-p_{4}\right)+p_{4}\left(1-p_{2}\right)\left(1-p_{3}\right)\right]+\cdots \\
& +t\left(x_{1} / t\right)\left(1-p_{1}\right)\left(1-p_{2}\right)\left(1-p_{3}\right)\left(1-p_{4}\right) .
\end{aligned}
$$

Substituting for $t$ and $p_{1}$ to $p_{4}$, and solving the equations for $x_{1}, x_{2}, x_{3}$ and $x_{4}$, gives the values stated in Section 4 of the text.

\section{B.2. Solution as a non-cooperative game}

To find the set of equilibrium strategies, let $t$ be the total estate, let $c_{i}$ be the sizes of the brothers' claims, and let $c$ be an $n$-vector of strategies such that $\left|C_{i}\right|=c_{i}$. Each strategy $C_{i}$ in $c$ will be a finite set of disjoint intervals in $[0, t]$. These are the parts of the estate brother $i$ is claiming based on will $i$.

For a given strategy vector $c$, let $a_{i}$ be an $n$-vector whose components represent the amount of the estate claimed by exactly $i$ brothers.

Suppose the brothers choose a strategy vector such that two values $a_{j}$ and $a_{j}^{\prime}$ both are positive, with $j^{\prime}<j-1$. Vector $c$ will not be an equilibrium since a brother who claims some positive amount claimed by a total of $j$ brothers could benefit by switching some of that claim to parts of the estate claimed by only $j^{\prime}$ brothers. An equilibrium strategy is one that results in a vector $a$ of the form $\left\{0, \ldots, 0, a_{j-1}, a_{j}, 0, \ldots, 0\right\}$ with $a_{j-1}>0$. Since the elements of $a$ must sum to $t$, we can set $a_{j-1}=a$ and $a_{j}=t-a$. Setting $c=\sum c_{i}$, the total estate claimed. it follows that

$$
(j-1) a+j(t-a)=c \text { or } j=(c+a) / t \text {. }
$$

Since $0<a \leq t$ and $j$ is integral, it follows that $j$ can be chosen uniquely as the least integer greater than $c / t$. We will designate this value as $j^{*}$. For Ibn Ezra's example, $c=250$ and $t=120$, so that $a=110$ and $j^{*}=3$. This determines the players' set of equilibr ium strategies. They must calculate $j^{*}$ and $a$, and lay claims so that amount $a$ of the estate is claimed by $j^{*}-1$ players and amount $t-a$ by $j^{*}$ players.

To calculate payoffs, let $y_{i j}$ be the amount claimed by player $i$ and also by a total of exactly $j$ players, for some equilibrium strategy $a$. Then

$$
\begin{aligned}
& y_{t, 1}=0 \text { for } j \neq j^{*}-1, j^{*}, \\
& y_{t, j^{*}, \ldots}, y_{i, j^{*}} \geq 0 \text { and } y_{i, j^{*}-1}+y_{i, j^{*}}=c_{i} .
\end{aligned}
$$


Letting $x_{i}$ be the final payment to heir $i$,

$$
x_{i}=y_{i, j^{*}-1} /\left(j^{*}-1\right)+y_{i, j} / j^{*} \text { and } \sum_{i \in, N} x_{i}=t
$$

The set of payoffs arising from equilibria are the vectors $x$ satisfying the above conditions on $x_{i}, y_{i, j}$ and $y_{i, j * \ldots}$. For Ibn Ezra's problem, this is the region bounded by the equilateral triangle given in Section 4 .

\section{B.3. Solution as a cooperative game}

Harsanyi's bargaining solution is calculated in two steps. First, a characteristic function for the game is determined. Then a Shapley value for this characteristic function is calculated to give the bargaining. solution.

The characteristic function states the amount each proper subset of the $n$ plavers will receive if there is no agreement. Harsanyi suggests that any coalition should threaten to play in the case of a disagreement in such a way as to maximize the difference between their total payoff and that of the opposing coalition. The opposing coalition will likewise threaten as if they were playing to maximize the negative of this difference. This is a two-person zero-sum game and can be solved by the minimax method. Since threats are binding, the characteristic function for a coalition gives the total payoff it would receive if it acted as if it were playing this difference game.

To determine $v(12)$ and $v(34)$, the function for heirs 1 and 2, and for heirs 3 and 4 , note that the heirs within a coalition can coordinate their choices as to which parts of the estate they are laying claim to.

It can be shown by arguments similar to those used in the analysis of the Nash equilibria for this problem, that heirs within a coalition should lay claims which have minimum overlap. Thus heirs 3 and 4 should claim $30+40=70$ units in all with no overlap. Heir 1 will clearly claim all of the estate and heir 2 will claim 60 units. The important parameter effecting the payoffs is $z_{2,34}$ defined as the overlap between heir 2's claim of 60 and heir 3 and 4's claim of 70 . The difference in payotfs $x_{1}+x_{2}-x_{3}-x_{4}$ can be calculated to be

$$
x_{1}+x_{2}-x_{3}-x_{4}=50 z_{2,34} / 3 \text {. }
$$

Thus $\{1,2\}$ will try to maximize the overlap and $\{3,4\}$ will try to minimize it. Each coalition should claim units at random and the expected overlap will then be

$$
E\left(z_{2,34}\right)=120 \times(70 / 120) \times(60 / 120)=35 \text {. }
$$

The expected difference between the coalitions' payoffs will be $50+35 / 3=61 ;$. This is $v(12)-v(34)$, and combining this with the requirement that $v(12)+v(34)=120$ gives $v(12)=90 \frac{5}{6}$ and $v(34)=29 \frac{1}{6}$. The other values of $v$ can be calculated in a similar way: 


$$
\begin{array}{ll}
v(\theta)=0, & v(1234)=120, \\
v(1)=58\}, & v(234)=61 \xi, \\
v(2)=24 !, & v(134)=95 \%, \\
v(3)=15, & v(124)=105, \\
v(4)=10 \xi, & v(123)=109 !, \\
v(12)=90 \xi, & v(34)=29 \xi, \\
v(13)=80, & v(24)=40, \\
v(14)=75 \%, & v(23)=44 !
\end{array}
$$

Calculating the Shapley value of $v$ gives the bargained solution, as quoted in Table I.

\section{Appendix C. Uniqueness of proportional division}

Theorem C.1. Let $t$ be the total estate and $c$ be an $n$-vector of claim sizes such that $\sum c_{1} \geq 1$ and $0 \leq c_{1} \leq t$. Let $f^{(n)}(c)$ for $n=1,2, \ldots$ be a series of functions giving a method $y$ dividing the estate for each number of claimants $n$. Then (AI)-(AS) hold if and only if (B) holds.

(A1) $f^{(n)}(C)$ is symmetrical in the components of $c$.

(A2) for all values of the components of $c$ other than $c_{i}, f^{(n)}(c)$ is a continuous function of $c_{i}$ at at least one value of $c_{i}$.

(A3) $f^{(n)}$ is Pareto-optimal, i.e., $\sum f_{i}^{(n)}(c)=t$.

(A4) $f^{(n)}$ is independent of the inclusion of heirs with no claim, i.e., $f_{i}^{(n)}(c)=$ $f_{1}^{(n)}$ " $\left(c^{\prime}\right)$ for $i=1$ to $n-1$, where $c_{n}=0$ and $c^{\prime}$ is formed from $c$ by deleting the last component $c_{n}$.

(AS) $f^{(n)}(C)$ is strategy-proof, i.e., for any heir $i$ and subset of heirs, $S, i \in S \subseteq N$,

$$
f^{(n-s)}\left(c^{\prime}\right)=\sum_{\in \in S} f_{j}^{(n)}(c)
$$

where $c$ ' is the vector formed from $c$ by replacing the claims of heirs in the subset $S$ by a single claim of $\sum_{, \epsilon} c_{j}$ for heir $i$.

(B) $f^{(n)}$ is the method of proportional division:

$$
f_{i}^{\left(n_{i}\right.}(c)=i c_{i} / \sum_{j} c_{j}
$$

Proof. Suppose each of functions $f^{(n)}$ satisfies (A1)-(A5). For fixed $c_{1}+c_{2}$ and fixed $c_{3}, \ldots, c_{n}$, define $g_{1,12}\left(c_{1}\right)$ as heir I's award:

$$
g_{1,12}\left(c_{1}\right)=f_{1}^{(n)}\left(c_{1}, c_{2}, \ldots, c_{n}\right) \text {. }
$$

Heiv 2 will receive $g_{2,12}\left(c_{2}\right)=f_{2}^{(n)}\left(c_{1}, c_{2}, \ldots, c_{n}\right)$ which by symmetry equals $f_{1}^{(n)}\left(c_{2}\right.$, $\left.c_{1}, \ldots, c_{n}\right)$ and therefore equals $g_{1,12}\left(c_{2}\right)$. 
Heirs 1 and 2 in alliance will receive $f^{(n-1)}\left(c_{1}+c_{2}, c_{3}, \ldots, c_{n}\right)$, which by (A4) and (A1), symmetry, equals $f_{1}^{(n)}\left(c_{1}+c_{2}, 0, c_{3}, \ldots, c_{n}\right)$, which equals $g_{1,12}\left(c_{1}+c_{2}\right)$.

Since $\boldsymbol{f}^{(n)}$ is strategy-proof, i.e., satisfies (A5),

$$
g_{1,12}\left(c_{1}+c_{2}\right)=g_{1,12}\left(c_{1}\right)+g_{2,12}\left(c_{2}\right)=g_{1,12}\left(c_{1}\right)+g_{1,12}\left(c_{2}\right) \text {. }
$$

Since $f^{(n)}$ is a continuous function of $c_{1}$ at at least one point, (A2), by Cauchy's theorem of functional equations (Aczél, 1966), $g_{1,12}\left(c_{1}\right)=k c_{1}$ for some function $k$ of $c_{1}+c_{2}, c_{3}, \ldots, c_{n}$. By symmetry we can show that for $j \neq 1, g_{1,1},\left(c_{1}\right)=k c_{1}$ where $k$ is a function of $c_{1}+c_{j}$ and the remaining variables other than $c_{1}$ and $c_{j}$.

This can be applied successively to show that $k$ is a function of $c_{1}+c_{2}+\cdots+c_{n}$, as follows. Choose $c$ and $c^{\prime}$ such that $\sum c_{i}=\sum c_{i}^{\prime}=c$. Then

$$
\begin{aligned}
k\left(c_{1}, c_{2}, \ldots, c_{n}\right) & =k\left(c_{1}+c_{2}, 0, c_{3}, \ldots, c_{n}\right) \\
& =k\left(c_{1}+c_{2}+c_{3}, 0,0, c_{4}, \ldots, c_{n}\right) \\
\ldots & =k(c, 0, \ldots, 0) \\
& =k\left(c-c_{2}^{\prime}, c_{2}^{\prime}, 0, \ldots, 0\right) \\
\ldots & =k\left(c_{1}^{\prime}, c_{2}^{\prime}, \ldots, c_{n}^{\prime}\right) .
\end{aligned}
$$

By Pareto-optimality, (A3),

$$
\sum_{i \in N} k\left(c_{1}+c_{2}+\cdots+c_{n}\right) c_{1}=t, \quad k\left(c_{1}+c_{2}+\cdots+c_{n}\right)=t / \sum_{i \in i} c_{i} .
$$

Thus $f_{i}(c)=t c_{i} / \sum_{j \in N} c_{j}$, which is the method of proportional division.

It can be verified that proportional division satisfies each of the conditions (A1)-(A5).

\section{Notes}

Note 1. The section quoted here occurs just after a rule dealing with two individuals who have found an object and lay total claim to it. In this case the answer given is that the court should divide the value equally.

It makes sense that the individuals should sometimes lay equal claims to the object but the Talmud does not make clear how unequal claims could arise. Perhaps one person states that he found the object first while the other declares that the two found it simultaneously.

In a later discussion of this rule another situation is mentioned that might give rise to unequal claims on an object. A seller has unwittingly sold the same object to two people. If the court knew which sale occurred first, the problem would be solved but there is no point, says the Talmud, in seeking out the seller's restimony since the very fact that he made the mistake shows him to be unreliable, so the court must base its division on the buyer's claims. It is not difficult to generalize this situation and imagine that the seller sold all of the commodity to one buyer and one-half of it the other. 
Another possible Talmudic source for Ibn Ezra's problem is a Mishnah in the Kethuboth, which deals with marriage contracts involving a promise of a sum of money to each of a man's brides.

If a man who was married to three wives died and the kethubah of one was a maneh (100 zuz), of the other two hundred zuz, and of the third three hundred zuz, and the estate (was worth) only one maneh (one hundred zuz), the (the sum) is divided equally. If the estate (was worth) two hundred zuz (the claimant) of the maneh (one hundred zuz) receives fifty zuz (and the claimants respectively) of the two hundred and the three hundred zuz (receive each) three gold denarii (seventy-five zuz). If the estate (was worth) three hundred zuz (the claimant) of the maneh receives fifty zuz and (the claimant) of the two hundred zuz (receives) a maneh (one hundred zuz) while (the claimant) of the three hundred zuz (receives) six gold denarii (one hundred and fifty zinz). Similarly if tisree persons contributed to a joint fund and they had made a loss or a profit they share in the same manner.

(Kethuboth, Fol. 93a, Babylonian Talmud, I. Epstein, ed., 1935)

Note 2. We suspect that Ibn Ezra was inspired by the found garment problem and not the marriage contract rule, since the latter division seems to be on different principles than the one he advocates. However, the problem it sets out is like Ibn Ezra's in one way: it disrrenses amounts rather than fractions to each individual.

Ibn Ezra's choice of 'ractions, 1, $\frac{1}{2}, \frac{1}{3}, \frac{1}{4}$, seems suggestive, as if the father had successively added or cut out sons from the will. A simpler explanation is suggested by the research of Gandz (1944). It appears it was very natural for ancient and medieval writers to choose these common fractions of the form $1 / n$, as somehow more normal or philosophically correct.

Rabbi Abrakam ben Meir Ibn Ezra was born in Toledo, Spain around the year 1090 A.D. He traveled widely and was a prolific writer on biblical studies, geography, astrology and science. Some details of his life are given by HellerWilensiky (1971).

Note 3. Problems of inheritance were widely discussed in Ibn Ezra's time. Rabirovitch (1973) states his view that by 'gentile sages' Ibn Ezra is referring to Moslem scholars.

Note 4. In this regard Ibn Ezra's method is remarkably similar to the Shapley value for $n$-person games (Shapley, 1953). A key step in Shapley's logic is that any $n$-person game of a certain class can be expressed as the sum of symmetrical games.

Another basic idea of arbitration appearing in the Talmud is the principle of equal division: 
R. Tahlifa, the Palestinian, recited in the presence of R. Abbahu: two (people) cling to a garment; (the decision is that) one take as much as his grasp reaches and tre other take as much as his grasp reaches and the rest is divided equally between them.

(Baba Bezia, Fol. 7a, Babylonian Talmud, 1. Epstein, ed., 1935)

Note 5. We could also assume the stronger but simpler requirement that the division is a continuous function of the claims, but this might be regarded as too strong, e.g., we may want to allow a method that is discontinuous at a point where the claims become consistent, where $\sum c_{i}=t$.

Note 6. The argument here has the structure of an indirect argument in the sense of von Neumann and Morgenstern (1944). It assumes there is a correct way to solve the problem and uses this assumption to deduce properties of the solution.

\section{Acknowledgment}

The author would like to thank Robert Aumann, Heino Lilles, Dov Samet and Nancy Stokey for helpful ideas.

\section{References}

J. Aczél, Lectures on Functional Equations and their Applications (Academic Press, New York. 1966).

F. Elkouri, How Arbitration Works (Bureau of National Affairs, W'ashington, 1952).

I. Epstein, ed., The Babylonian Talmud (Soncino, London, 1935).

S. Gandz, Complementary fractions in Bible and Talmud, in: Louis Ginzberg Jubilee Volume (American Academy for Jewish Research, New York, 1945).

J. Harsanyi, Rational Behavior and Bargaining Equilibrium in Games and Social Situations (Cambridge University Press, Cambridge, 1978).

S. Heller-Wilensky, Abraham Ibn Ezra, Encyclopaedia Judaica 8 (1971) 1163-1170.

I. Mann and L.S. Shapley, Values of large games VII: Evaluating the electoral college exactly, Rand Corporation Rept. RM-3158-PR, Rand Corporation, Savia Monica, CA (1962).

J. Nash, Equilibrium points in $n$-person games, Proc. Nat. Acad. Sci. U. '́.A. $36(1950) 48-49$.

N. Rabinovitch, Probability and Statistical Inference in Medieval Jeush Literature (University of Toronto Press, Toronto, 1973).

"Sage of Jerusalem". Article 12, Torah Mizion 1(2) (1887).

L.S. Shapley, A value for n-person games, Ann. Math. Stud. 28 (1953) 304-3!7.

J.V. Spielmans, Labor disputes on rights and on interests, Amer. Econom. Rev. 29 (1939) 299-312.

J. von Neumann and (). Morgenstern, Theory of Games and Ecor:omic Behavior (Princeton University Press, Princeton, 19.44). 